\title{
UniSchooLabs Toolkit: Tools and Methodologies to Support the Adoption of Universities' Remote and Virtual Labs in Schools.
}

\author{
http://dx.doi.org/10.3991/ijoe.v8iS3.2271 \\ A. Chioccariello, A. Ceregini and M. Tavella \\ Consiglio Nazionale delle Ricerche / Istituto per le Tecnologie Didattiche, Genoa, Italy
}

\begin{abstract}
The UniSchooLabs project aims at creating an infrastructure supporting web access to remote/virtual labs and associated educational resources to engage learners with hands-on and minds-on activities in science, technology and math in schools. The UniSchooLabs tool-kit supports the teacher in selecting a remote or virtual lab and developing a lab activity based on an inquiry model template. While working with the toolkit the teacher has access to three main features: a) a catalogue of available online laboratories; b) an archive of activities created by other users; c) a tool for creating new activities or reusing existing ones.
\end{abstract}

Index Terms-Laboratories, Science education, Remote and virtual labs, Virtual learning environment

\section{INTRODUCTION}

Laboratories are an essential part of the teaching and learning experience in many branches of science and engineering. Ideally, laboratories provide a window on science-in-the-making, showcase the ambiguity of empirical work, develop practical skills, and foster teamwork abilities. On-line laboratories are becoming a major component of the college level teaching and learning experience since they enable students to make use of the equipment 24/7 [1].

UniSchooLabs, a two-year project funded under the European Commission's Lifelong Learning Programme, aims at improving quality in science education in Europe by promoting collaboration between universities and schools in the provision of remote access to university science laboratories for primary and secondary schools through internet-based services and mobile learning devices. UniSchooLabs (which started in October 2010) is carried out by Scienter S. Cons.r.l. together with European Schoolnet, MENON Network EEIG, Ellinogermaniki Agogi Panagae-Savva S.A., and Consiglio Nazionale delle Ricerche.

While remote and virtual labs are usually hosted by individual institutions, we assume that remote and virtual labs will eventually become a cloud of interoperable web based resources providing tools for integration into the school's Learning Management System. We are aware there is still major work to be done to this end. In particular remote laboratories, being physical resources, require scalable shared architectures that minimise the cost of building and maintaining laboratory equipment and infrastructure, while maximising the percentage of time in which equipment is used. For example a unified booking system [2] will be an important component of such architecture. Furthermore both remote and virtual labs should be seamlessly accessible from a browser without having to install extra layers of software or plug-ins on the client side. International organizations like the Global Online Lab Consortium and the International Association of Online Engineers are working toward this end.

Our goal is to support school adoption of remote and virtual labs. To this end we draw upon the results of educational research on practical work in science teaching and learning to derive requirements for a toolkit to scaffold teacher and learner use of on-line labs. We conclude with reporting on preliminary feedback from field-testing in 10 European schools that points to ways of improving the toolkit.

\section{EDUCATIONAL RESEARCH}

The educational research literature on the role of the laboratory in science teaching and learning points out that labs should involve both hands-on investigation and minds-on reflection. Furthermore, it warns that incorporating inquiry-type activities in school science is inhibited by limitations in resources - including access to appropriate science curricula. Other inhibiting factors include large classes, inflexible scheduling of laboratory facilities, and the perceived foci of external examinations [3].

Common-sense understanding of the natural world, including fundamental ideas such as cause and effect, conservation of number, substance, weight, volume, classification and groupings and their interrelations are "naturally" developed since these basic ideas are regularly tested against experience in everyday situations; they are clearly functional in dealing with these and so are reinforced. Scientific knowledge, however, has developed for more specific and specialized purposes. Many of its explanations are counter-intuitive and not supported by everyday experience (at least not until you have learned to "read" that experience in very specific ways) [4]. Furthermore, common-sense ideas are not isolated; they constitute a network of mutually supporting concepts. Failure of a single idea to explain a phenomenon does not trigger a conceptual change unless a corresponding reorganisation of the network of concepts takes place. For example, it is well known that a naive explanation of the phases of the moon is based on the idea of shadow (that of Earth). However, simply letting one observe that early in the morning, sometimes, both the moon and the sun are visible does not imply a conceptual change. 
Learning to read the experience in the ways of a scientist requires opportunities for specific hands-on activities and support for minds-on activities that foster scientific reasoning by practising these specific ways of building ideas, testing, discussing and arguing about them. Recent research into the current practices of English [5] and German [6] science teachers provides evidence that laboratory work might be counterproductive, in terms of science learning, if there is no provision for scaffolding that makes connections between hands-on and minds-on activities.

The so-called Rocard report entitled Science Education Now: A Renewed Pedagogy for the Future of Europe [7] calls for an inquiry approach to science education. "The science education community mostly agrees that pedagogical practices based on inquiry-based methods are more effective, the reality of classroom practice is that in the majority of European countries, these methods are simply not being implemented." The report borrows the definition of inquiry from Linn, Davis \& Bell [8] "we define inquiry as the intentional process of diagnosing problems, critiquing experiments, distinguishing alternatives, planning investigations, researching conjectures, searching for information, constructing models, debating with peers, and forming coherent arguments. In science inquiry projects, students communicate about scientific topics, evaluate scientific texts, conduct investigations, ask questions about science or technology policies, create designs, and critique arguments, often using technology resources."

The Nuffield report [9] states that: "Research would also suggest that deep, as opposed to superficial understanding, comes through knowing not only why the right answer is right but also through knowing why the wrong answer is wrong. Such learning requires space to discuss, to think critically and to consider others' views."

The Framework for K-12 Science Education [10] put forward the idea of science as a set of practices and focuses on "important practices, such as modelling, developing explanations, and engaging in critique and evaluation (argumentation), that have too often been underemphasized in the context of science education. In particular, we stress that critique is an essential element both for building new knowledge in general and for the learning of science in particular. Traditionally, K-12 science education has paid little attention to the role of critique in science."

Recent research [11, 12] shows that opportunities for students to engage in collaborative discourse and argumentation offer a means of enhancing students' conceptual understanding and their skills and capabilities in scientific reasoning. Considerable work has been undertaken in the past decade by the Computer-Supported Collaborative Learning community to develop software tools that either enable the visualization of argument or scaffold argumentation [13].

\section{TOOLKIT}

Remote \& Virtual Labs facilities become actual educational resources when used in pedagogically meaningful ways. In a learning process, educational effectiveness cannot be thought of as an exclusive attribute of the educational resources which are used, but rather of the whole pedagogical plan that involves the use

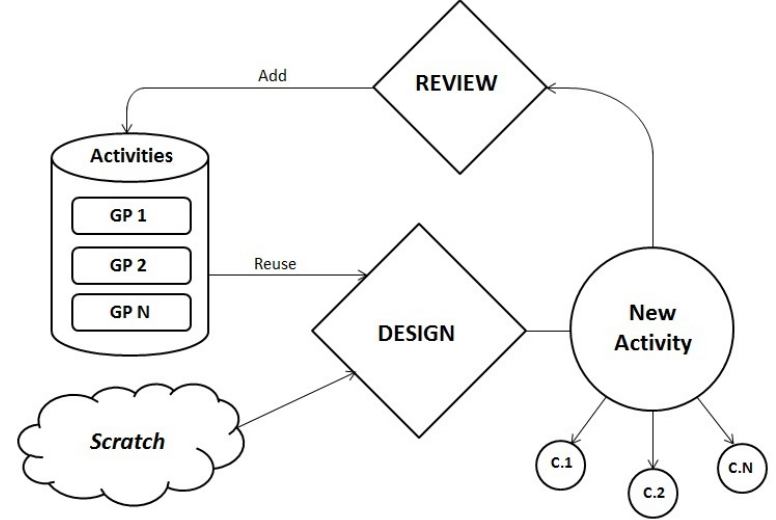

Figure 1. Lab activities life cycle. A new lab activity is created either from scratch or reusing an existing one. To enroll students activities are cloned $(\mathrm{C} 1 . . \mathrm{CN})$. New activities are reviewed; they are added to the activities catalogue if they are considered good practices (GP1..GPN).

of those resources. The concept of pedagogical plan has been widely investigated within a specific research area referred to as Learning Design [14]. Pedagogical plans are also identified in the literature with a variety of substantially equivalent terms such as learning scenarios, pedagogical scenarios, learning design.

The pedagogical plan can be thought of in two different but complementary ways: (i) as communication oriented objects intended to share among teachers a given (successful) learning path, to propagate innovative approaches and to support individual and collaborative design [15], and (ii) as computational objects which can be designed by authors (teachers) and executed in a specific learning environment $[16,17]$. The term executed may have different meanings in different proposals: from computer delivered instruction to environments which cooperate with the teacher to guide the learners throughout the different stages of the learning path, providing them access to the facilities and resources required at each stage and supporting them while performing the different required activities.

Thinking of pedagogical plans as purely descriptive entities seems to be inadequate to support a process of educational innovation. Therefore we propose to adopt a perspective of integration between the above mentioned visions by thinking of pedagogical plans as computational objects intended (i) to support interpersonal communication among teachers and (ii) to become a sort of engine of the actual learning process.

A toolkit for the development of pedagogical plans for lab activities should support three categories of users:

- authors: a simple authoring/editing environment for (i) structuring the plan, (ii) specifying the access to the required resources and learning materials and (iii) describing the rationales of the key choices adopted in the plan (of paramount importance for sharing and reuse);

- learners: an environment where the learner can choose to access a given resource, take lab notes, discuss with peers, receive support;

- teachers: they must be able to monitor learners' activities, to participate in group activities, to give suggestions or otherwise stimulate selected individuals or the whole group and so on. 
The UniSchooLabs toolkit comprises a catalogue of available remote and virtual labs kindly provided by their developers along with good practices to inspire the teacher in their use. The core of the toolkit is a pedagogical plan editor that enables the teacher to integrate learning materials, access to lab experiments, and students' lab notebooks within a virtual learning environment. Lab activities can be directly used by students. They can also become part of a library of plans for other teachers to reuse.

The pedagogical plan editor allows the teacher to devise plans based on templates modelled after inquiry based science education models. A minimalist template for structuring a lab activity is Predict-Observe-Explain [18]. Students are first asked to predict what they would expect to happen in a given situation and to write this down, then to carry out some observations, and finally to explain what they have observed (which may or may not be what they predicted).

A more detailed inquiry template [19] might include:

- Plan and design - What is our question or problem? What do we want to know? How will we find out? What do we predict will happen in the experiment? Do we have a hypothesis?

- Implement the experiment - What do we observe? Are we using the right tools? How much detail do we need to record? Why did we choose these parameters' values?

- Collect, organize and analyse data - How do we organize the data? What patterns do we see? What relationships might there be? What might this mean?

- Draw tentative conclusions - What claims can we make? What evidence do we have? What else do we need to know?

- Formulate new questions - Do we have a definite answer to our question? (Why or Why not) What questions do we still have? What new questions do we have? How can we find out?

- Draw final conclusions - What do we know from all our investigations? What evidence do we have to support our ideas?

An inquiry template provides a structure that scaffolds both the authoring of an activity and its use by learners. However, it should not be interpreted as a sequence of steps in a recipe. The inquiry process is iterative and its phases are interdependent. Furthermore a given inquiry might omit phases [20]. Science inquiry, whether that of the student or of the scientist, is a complex process and various parts may need to be revisited, dwelt upon, or even skipped at times. For example, if the results of students' investigation do not validate their original prediction, they need to question their assumptions, return to the beginning of their investigation and develop a new experiment. If they design an investigation plan and it doesn't work, they need to redesign it. If they come to a tentative conclusion but it differs from that of another team, both teams may need to redo their investigations [19].

Inquiry Based Science Education (IBSE) is a popular approach adopted in a number of European projects (e.g. COSMOS [21], Fibonacci [19], and nQuire [20]) and teacher training initiatives. Although the proposed IBSE models vary, they are variation of a basic theme (Table 1).

A school laboratory usually comes with textbook and notebook. The textbook includes manuals, learning materials for the subject of study, assignments. The lab notebook is used for recording, in some form, the question or purpose of the investigation, the predictions, the ideas, the investigation designs, the data collected, the analysis of the data, emerging ideas and reflections, and intermediate and final conclusions.

The UniSchooLabs toolkit integrates remote and virtual labs with a Learning Management System to provide an electronic version of the lab textbook and notebook. The toolkit supports the teacher in selecting a remote or virtual lab and developing a lab activity based on an inquiry model template. Online lab activities comprise web pages with associated document folders. The teacher creates the learning materials and the students write in the lab notebook. The document folder is a means for making available a variety of learning materials: readings, forms, computational models (e.g. spread-sheets), experimental data, and graphs.

The authoring process starts with the outline of the activity derived from the adopted inquiry model (Table II). Then the teacher can write the notes for each phase of the model and upload readings and assignments.

TABLE I.

COMPARISON OF IBSE MODELS

\begin{tabular}{|c|c|c|}
\hline COSMOS & Fibonacci & nQuire \\
\hline $\begin{array}{l}\text { - Exhibit curiosity } \\
\text { - Define questions } \\
\text { from current } \\
\text { knowledge } \\
\text { - Propose } \\
\text { preliminary } \\
\text { explanations or } \\
\text { hypotheses } \\
\text { - Plan and conduct } \\
\text { simple } \\
\text { investigation } \\
\text { - Gather evidence } \\
\text { from observation } \\
\text { - Explanation } \\
\text { based on } \\
\text { evidence } \\
\text { - Consider other } \\
\text { explanations } \\
\text { - Communicate } \\
\text { explanation }\end{array}$ & $\begin{array}{l}\text { - Engage } \\
\text { - Plan and design } \\
\text { - Implement } \\
\text { - Organize and } \\
\text { analyse data } \\
\text { - Draw tentative } \\
\text { conclusions } \\
\text { - Formulate new } \\
\text { questions } \\
\text { - Draw final } \\
\text { conclusions } \\
\text { - Communicate } \\
\text { with other } \\
\text { audiences }\end{array}$ & $\begin{array}{l}\text { - } \text { Find topic } \\
\text { - Decide inquiry } \\
\text { question or } \\
\text { hypothesis } \\
\text { - Plan methods, } \\
\text { equipment and } \\
\text { actions } \\
\text { - Collect evidence } \\
\text { - Analyse and } \\
\text { represent } \\
\text { evidence } \\
\text { - Decide } \\
\text { conclusions } \\
\text { - Share and } \\
\text { discuss inquiry } \\
\text { - Reflect on } \\
\text { progress }\end{array}$ \\
\hline
\end{tabular}

TABLE II.

LAB ACTIVITY OUTLINE FROM MODEL

\begin{tabular}{|l|l|}
\hline Inquiry model & Activity Plan \\
\hline Exhibit curiosity & $\begin{array}{l}\text { The Challenge: Is the Moon } \\
\text { really larger when you see it on } \\
\text { the horizon? }\end{array}$ \\
\hline $\begin{array}{l}\text { Define question from current } \\
\text { knowledge }\end{array}$ & Your thoughts about the moon \\
\hline Plan investigation & Planning \\
\hline Conduct investigation & Carrying out your exploration \\
\hline $\begin{array}{l}\text { Gather evidence from } \\
\text { observation }\end{array}$ & Measuring moon's images \\
\hline Explanation based on evidence & Making sense of your results \\
\hline
\end{tabular}




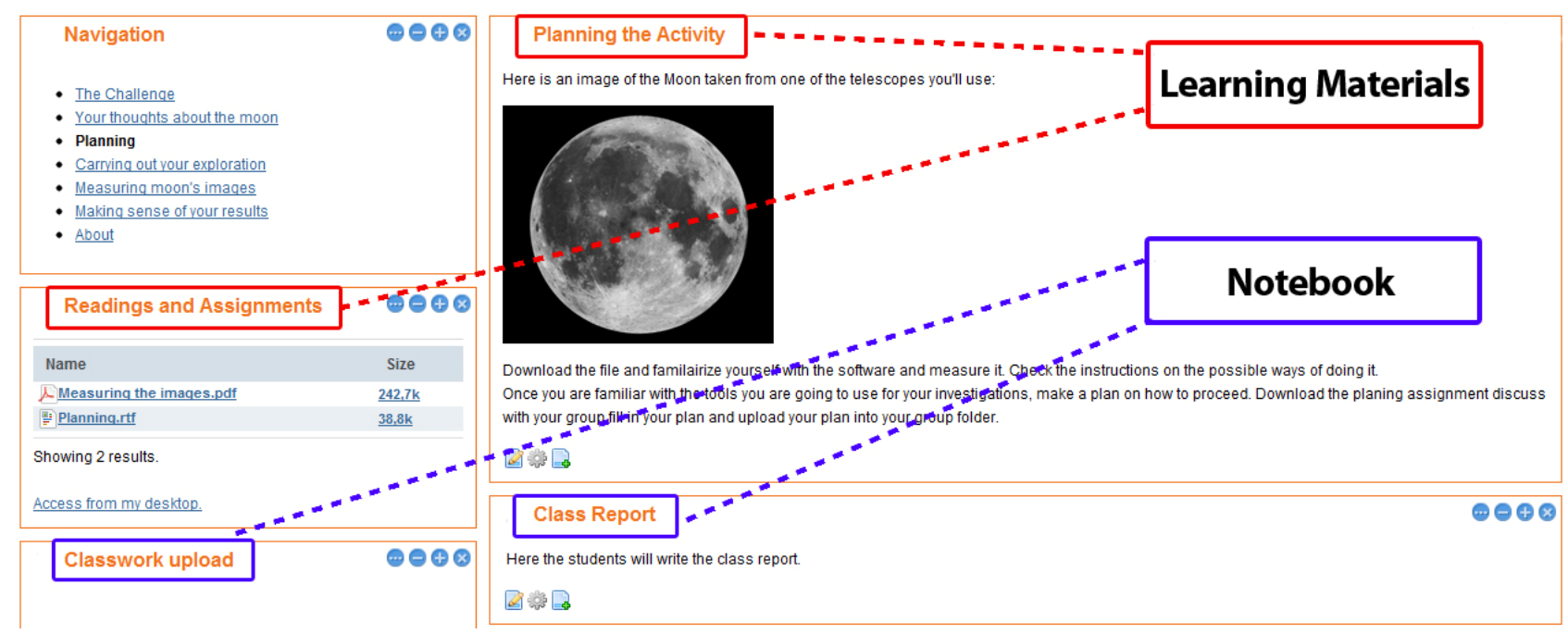

Figure 2. A page of the UniSchooLabs activity "Is the Moon really larger when you see it on the horizon?" with its four sections hosting the learning materials (Planning the Activity, Readings and Assignments) and the lab notebook (Class report, Classwork upload).

A UniSchooLabs activity is composed of a number of web pages. Through these pages the teachers are able to present the tasks at hand while providing the students with supporting learning materials and assignments. Students can navigate through the pages and follow the instructions given while writing, on the same page, their own notes and group reports on different matters (questions or purposes of the investigation, predictions, ideas, investigation designs, data collected, analysis of the data, emerging ideas and reflections.

Let's examine in detail the different sections of an activity page (fig. 2):

- What to do in this phase of the inquiry process. This is the main section of every page.

- Readings and Assignments - This section is the storage place of all accompanying materials. This contains any supporting documents for the students, like worksheets, questionnaires or a lab guide. Each page has its own separate "Readings and Assignments" section.

- Class Report - Students may edit this section and add comments including images, videos or links. Based on the activity and the guidance provided by the teacher, the students can write down their thoughts, keep notes while experimenting, answer questions or write their predictions.

- Classwork Uploads - This section allows students to collect information generated by experiment tools or as part of an assignment and record it in their lab notebook. Students might be requested to upload experiment data that they need to import from the remote/virtual lab being used. As part of an assignment, teachers might provide forms to fill in within the "Readings and Assignments" section, requesting students to upload their answers. If, for example, students are divided into groups, they might be required to create multiple folders. In this way, each group may have its own folder in the "Classwork Uploads" section, thus allowing better organization of the materials produced.

To use a lab activity with a class, we have to enable the enrolled students to access the learning materials and add text, experimental data, graphs and mathematical expressions to the lab notebook. This is achieved by cloning the authored lab-activity and instantiating it for the class. This same mechanism allows for reuse of the learning material. A teacher can adopt and/or adapt an existing activity, as well as create new instances for a number of classes (Fig.1). Students can write in the lab notebook (Fig. 2) as individuals, groups, and the whole class. These three cases may be as follows:

- Students keep track of: questions or purposes of the investigation; predictions; ideas; investigation designs; data collected, analysis of the data, emerging ideas and reflections.

- Several activities are carried out in small groups both for practical reasons (availability of resources) and fostering team work. Group work is also an opportunity for collaboration and discussion. The group records information in the notebook for presenting ideas and tentative conclusions to the whole class.

- Class discussions, based on individual and group records, are held to reach conclusions under the teacher's guidance. Class discussions are held to compare and discuss questions, predictions, hypotheses, data and interpretations. They produce tentative conclusions, new questions, final conclusions, and reports for a wider audience.

\section{CONCLUSIONS}

The UniSchooLabs portal ${ }^{1}$ is hosted by the European Schoolnet. The toolkit pilot has involved ten schools in Germany, Greece and Italy.

The school teachers involved have used the toolkit to select a remote or virtual lab and design their own lab activities. In this process they have had to learn how to use both our toolkit and the chosen lab. While this process was not a straightforward one and required assistance from our side, they managed to complete the task. Lack of a single sign-on service and integration with the labs was a

${ }^{1}$ The toolkit is available at http://unischoolabs.eun.org. To access the toolkit as a teacher, please login with the following credentials: username: toolkit - password: itslabtime. 
nuisance but it did not seriously impact the use of the tools. Classroom usage did match teachers' expectations; remote labs were usually perceived as more motivating than virtual ones.

While we stressed classroom discussion and reporting, we didn't find strong evidence of these activities in the notebook data. Our interpretation is that this approach, as for the inquiry model for authoring, might be fostered by developing dedicated tools for scaffolding scientific argumentation. A future revision of the toolkit might include support for an argumentation environment based on Toulmin's model [11] that scaffolds collaborative discussion [12] and enables the graphical visualization of arguments [13].

\section{ACKNOWLEDGMENT}

Our thanks are due to the teachers and pupils involved in testing the toolkit during the pilot; to the members of the UniSchooLabs project; to our colleague Jeffrey Earp; and to our colleague and mentor on the role of pedagogical design in technology enhanced learning, Giorgio Olimpo.

\section{REFERENCES}

[1] J.G. Zubía and G.R. Alves (Eds), Using Remote Labs in Education - Two Little Ducks in Remote Experimentation, Bilbao: University of Deusto, Spain, 2011.

[2] V. Mateos, A. Gallardo, T. Richter, L. Bellido, P. Debicki, and V. Villagra, "LiLa Booking System: Architecture and Conceptual Model of a Rig Booking System for On-Line Laboratories." in International Journal of Online Engineering (iJOE), vol. 7, issue 4, 2012, pp. 26-35.

[3] A. Hofstein and V.N. Lunetta, "The laboratory in science education: Foundations for the twenty-first century", in Science Education 88(1), 2003, pp. 28-54.

[4] R. Millar, "The Role of Practical Work in the Teaching and Learning of Science", National Academy of Science, Committee on High School Science Laboratories: Role and Vision, 2004.

[5] I. Abrahams \& R. Millar. "Does Practical Work Really Work? A study of the effectiveness of practical work as a teaching and learning method in school science" in International Journal of Science Education 30(14), pp. 1945-1969, 2008. http://dx.doi.org/10.1080/09500690701749305

[6] R. Duit \& M. Tesch, "On the role of the experiment in science teaching and learning - Visions and the reality of instructional practice' in M. Kalogiannakis, D. Stavrou and P.G. Michaelides (Eds.), Proceedings of the 7th International Conference on Handson Science, Rethymno-Crete, 2010, pp. 17-29.

[7] European Commission, Science Education Now: A Renewed Pedagogy for the Future of Europe, Brussels: European Commission, 2007.

[8] M.C. Linn, E.A. Davis and P. Bell, "Inquiry and Technology", in Internet Environments for Science Education, M.C. Linn, E.A. Davis, and P. Bell (eds.), 2004, pp. 3-28.

[9] J. Osborne and J. Dillon, Science Education in Europe: Critical Reflections, The Nuffield Foundation, London, 2008.

[10] Committee on Conceptual Framework for the New K-12 Science Education Standards, Framework for K-12 Science Education:
Practices, Crosscutting Concepts, and Core Ideas, National Academies Press, Washington, D.C., 2012.

[11] J. Osborne, "Arguing to Learn in Science: The Role of Collaborative, Critical Discourse", in Science 328(5977), 2010, pp. 463-466.

[12] C. Chin and J. Osborne, "Supporting Argumentation Through Students' Questions: Case Studies in Science Classrooms", in Journal of the Learning Sciences 19(2), 2010, pp. 230-284. http://dx.doi.org/10.1080/10508400903530036

[13] J. Andriessen, M. Baker and D. Suthers (Eds.), Arguing to learn: Confronting Cognitions in Computer-Supported Collaborative Learning Environments. Dordrecht, Netherlands: Kluwer Academic Publishers. Computer supported collaborative learning book series, vol. 1, 2003.

[14] S. Britain, in H. Beetham and R. Sharpe (Eds.), "Learning design systems: current and future developments in rethinking pedagogy for a digital age", New York: Routledge, 2007, pp.103,115.

[15] G. Olimpo et al., "Pedagogical plans as communication oriented objects" in Computers \& Education 55, 2010, pp. 476-488.

[16] R. Koper, "Current research in learning design" in Educational Technology \& Society 9(1), 2006, pp. 13-22.

[17] R. Philip and J. Dalziel, "Designing activities for student learning using the Learning Activity Management System (LAMS)", Proc. of International Conference on Computers in Education, Melbourne, 2004.

[18] R. White and R. Gunstone, Probing Understanding. London: Falmer Press, 1992

[19] K. Worth, E. Saltiel and M. Duque, "Implementing Inquiry-Based Science Education", Technical report, The Fibonacci project, 2010 .

[20] E. Scanlon et al, "How technology resources can be used to represent personal inquiry and support students' understanding of it across contexts", in Journal of Computer Assisted Learning 27(6), 2010, pp. 516-529. http://dx.doi.org/10.1111/j.13652729.2011.00414.x

[21] D.G. Sampson et al. (Eds.), "Templates for the Development of Technology Enhanced Educational Scenarios", Technical report, The COSMOS project.

\section{AUTHORS}

A. Chioccariello is with the Consiglio Nazionale Ricerche / Istituto Tecnologie Didattiche, Via De Marini, 6 - 16149 Genoa, Italy (e-mail: augusto@itd.cnr.it).

A. Ceregini is with the Consiglio Nazionale Ricerche / Istituto Tecnologie Didattiche, Via De Marini, 6 - 16149 Genoa, Italy (e-mail: ceregini@itd.cnr.it).

M. Tavella is with the Consiglio Nazionale Ricerche / Istituto Tecnologie Didattiche, Via De Marini, 6 - 16149 Genoa, Italy (e-mail: tavella@itd.cnr.it).

This work was supported in part by the European Commission, Lifelong Learning Programme. This article reflects the views only of the author, and the Commission cannot be held responsible for any use which may be made of the information contained therein. Ite is an extended and modified version of a paper presented at the International Conference on Remote Engineering \& Virtual Instrumentation (REV2012), held at University of Deusto, Bilbao, Spain, July 4-6, 2012. Manuscript received 14 September 2012. Published as resubmitted by the authors 14 November 2012. 